\title{
NOTIFICAÇÃo COMPULSÓRIA DA CISTICERCOSE EM RIBEIRÃO PRETO - SP
}

\author{
OSVALDOM. TAKAYANAGUI", ANA ALICE M. C. CASTRO E SILVA**, ROSEU C. SANTIAGO***, \\ NEWTON S. ODASHIMA*, VERA C. TERRA*, ANGELA M. M. TAKAYANAGUI***
}

RESUMO - A cisticercose 6 grave problema de saúde pública em várias regiðes da Ásia, África e América Latina. Os estudos epidemiológicos baseados na frequência de casos nos serviços especializados de neurologia, neurocirurgia, tomografia computadorizada, nas necrópsias e nos estudos soroepidemiológicos não permitem a avaliação da real prevalência populacional. $O$ presente estudo teve como objetivo a análise da prevalência da cisticercose no município de Ribeirão Preto, através da notificaçăo compulsória implantada em caráter pioneiro no Brasil. O coeficiente de prevalência foi de 54 casos/100000 habitantes, no período de 20-outubro-1992 a 31 de-dezembro de 1995. Os resultados indicaram, adicionalmente, que a cisticercose não está sob controle no nosso meio pois $21 \%$ dos casos notificados apresentavam a forma ativa. A notificaçāo compulsoria revelou ser recurso valioso para o estudo epidemiológico da cisticercose, permitindo, adicionalmente, o mapeamento das áreas mais afetadas para melhor direcionamento das estratégias de prevenção.

PALAVRAS-CHAVE: cisticercose, Taenia solium, epidemiologia, prevalência, notificação compulsória.

\section{Compulsory notification of cysticercosis in Ribeirão Preto - SP, Brazil}

ABSTRACT - Cysticercosis is a severe public health problem in several regions of Asia, Africa and Latin America. Epidemiologic studies based on the frequency of cases observed in specialized neurology, neurosurgery and computed tomography services, at autopsy and in seroepidemiologic studies do not permit the determination of the true prevalence of the disease in the population. The objective of the present study was to investigate the prevalence of cysticercosis by compulsory notification. The coefficient of prevalence was 54 cases $/ 100000$ inhabitants in the municipality of Ribeirão Preto. The results also indicated that cysticercosis is not under control in our region since $21 \%$ of cases presented the active form of the disease. Compulsory notification proved to be a valuable resource for the epidemiologic study of cysticercosis, also permitting the mapping of more affected areas for a better direction of prevention strategies.

KEY WORDS: cysticercosis, Taenia solium, epidemiology, prevalence, compulsory notification.

A cisticercose humana, infestação pela forma larvária da Taenia solium, é grave problema de saúde pública em várias regiōes da Ásia, África e América Latina, particularmente nos países em desenvolvimento. Nestes, a precariedade das condiçōes sanitárias e o baixo nível sócio-econômicocultural aliam-se na persistência de sua disseminação. Embora possa acometer os mais diversos órgãos, o envolvimento do sistema nervoso central (SNC) é a forma mais grave da cisticercose. Pela estimativa da Organização Mundial da Saúde, a neurocisticercose (NCC) é responsável por 50000

* Departamento de Neurologia da Faculdade de Medicina de Ribeirăo Preto da Universidade de Săo Paulo - USP; **Divisão de Vigilância Epidemiológica da Secretaria da Saúde do Município de Ribeirāo Preto; ***Departamento de Vigilância em Saúde da Secretaria da Saúde do Município de Ribeirăo Preto; ****Disciplina de Saúde Pública da Escola de Enfermagem de Ribeirão Preto - USP. Aceite: 27-julho-1996.

Dr. Osvaldo M. Takayanagui - Departamento de Neurologia, Faculdade de Medicina de Ribeirão Preto USP 14.048-900 Ribeirăo Preto SP - Brasil. FAX 5516-6330866. 
óbitos/ano e também por cifra indeterminada, mas certamente muito maior, de indivíduos que sobrevivem apresentando graves complicaçōes ou sequelas neurológicas. No Brasil, a NCC é endêmica principalmente nos Estados de São Paulo, Minas Gerais, Paraná e Goiás. Entretanto, os dados epidemiológicos disponíveis são baseados fundamentalmente no levantamento de casos de serviços especializados de neurologia, neurocirurgia ou de tomografia computadorizada, não refletindo a verdadeira prevalência populacional.

O presente estudo tem como objetivo a apresentação dos dados sobre a prevalência da NCC em Ribeirão Preto, tendo por base os casos notificados à Secretaria da Saúde do Município, no periodo de 20-outubro-1992 a 31-dezembro-1995.

\section{MATERIAL E MÉTODOS}

De acordo com o Decreto 397, publicado no Diário Oficial do Município de 20-outubro-1992, todos os pacientes com o diagnóstico de cisticercose atendidos nos serviços de saúde (hospitais, ambulatórios e consultórios privados) de Ribeirăo Preto deveriam ser notificados ao Serviço de Vigilância Epidemiológica da Secretaria Municipal da Saúde, com o preenchimento de ficha de investigação epidemiológica pelo médico assistente.

Este é um estudo descritivo da análise dos casos notificados de NCC em Ribeirão Preto, no período de 20-outubro-1992 a 31-dezembro-1995. Com o intuito de evitar a duplicidade de notificaçăo de um mesmo caso, as informaçðes foram lançadas em um programa informatizado de banco de dados.

O diagnóstico de NCC fundamentou-se nos seguintes critérios: a) quadro clínico compatível ${ }^{\text {20,35,37,38,41; }}$ b) presença de lesões hipodensas e/ou de calcificações patológicas intracranianas sugestivas de NCC na tomografia computadorizada (TC) ${ }^{21,23}$ e/ou ressonância nuclear magnética (RNM); c) positividade do teste de ELISA para cisticercose no líquido cefalorraquidiano (LCR); d) detecção cirúrgica; e) achado necroscópico. Os casos considerados suspeitos de NCC foram encaminhados ao Ambulatório de Neurologia Tropical do Hospital das Clínicas da Faculdade de Medicina de Ribeirão Preto - USP para confirmação diagnóstica.

As manifestaçōes clínicas foram catalogadas de acordo com a classificação de Trelles \& Lazarte ${ }^{41}$, com algumas modificações ${ }^{37.38}$ : epilepsia, sindrome de hipertensão intracraniana (HIC), meningite cisticercótica, distúrbios psíquicos, comprometimento medular e suas combinaçōes entre si. A atividade da NCC foi analisada levando-se em consideração os aspectos clínicos, os achados do LCR e da TC, sendo os casos divididos nas formas ativa e inativa, de acordo com Sotelo et al ${ }^{35}$.

\section{RESULTADOS}

No periodo de 20-outubro-1992 a 31-dezembro-1995, foram notificados 809 casos de NCC, sendo 262 de residentes em Ribeirão Preto (Tabela 1). A população estimada nesta cidade era, em 31-dezembro-1995, de 484483 habitantes. O Coeficiente de Prevalência da NCC em Ribeirão Preto foi, portanto, de 54 casos/100000 habitantes.

O mapeamento do local de residência dos pacientes evidenciou o predomínio das zonas norte e oeste do Município, com um total de 202 casos $(77,1 \%)$.

Tabela 1. Município de residência dos 809 casos de neurocisticencose notificados em Ribeirão Preto no periodo de outubro-1992 a dezembro-1995.

Município de Residencia

Ribeirāo Preto

Outros Municípios da Regiāo de Ribeirão Preto

Outros Municípios do Estado de São Paulo

Outros Estados

Total
Número de casos

Percentagem (\%)
262

227

28,0

213

26,3

107

13,2

809 
Tabela 2. Idade e sexo dos 262 pacientes residentes em Ribeiräo Preto, notificados no período de outubro1992 a dezembro-1995.

\begin{tabular}{ccccc}
\hline Faixa etária (anos) & Feminino & Masculino & Total & Percentagem (\%) \\
\hline $0-9$ & 1 & 1 & 2 & 0,7 \\
$10-19$ & 10 & 9 & 19 & 7,2 \\
$20-29$ & 28 & 18 & 46 & 17,5 \\
$30-39$ & 40 & 32 & 72 & 27,5 \\
$40-49$ & 26 & 26 & 52 & 19,8 \\
$50-59$ & 21 & 12 & 33 & 12,6 \\
$60-69$ & 18 & 5 & 23 & 8,7 \\
$70-79$ & 7 & 6 & 13 & 4,9 \\
$80-89$ & 1 & - & 1 & 0,4 \\
$>90$ & 1 & - & 1 & 0,4 \\
Total & 153 & 109 & 262 & 100 \\
\hline
\end{tabular}

Dos 262 casos, $153(58,4 \%)$ eram do sexo femininoe 109 (41,6\%) do masculino (Tabela 2). A idade dos pacientes variou entre 4 e 93 anos, com mediana de 38 anos e média de 40,3 $\pm 16,3$ anos. A faixa etária mais acometida foi entre $20 \mathrm{e} 49$ anos $(64,8 \%)$.

No interrogatório de antecedentes, $40(15,2 \%)$ referiram eliminaçāo prévia de proglótides de Taenia.

A NCC foi considerada ativa em 55 (21\%) casos e inativa em 207 (79\%). No cômputo geral, a epilepsia foi a manifestação clínica mais frequente com 220 casos $(84 \%)$, seguida por síndrome de HIC com 23 casos $(8,7 \%)$, distúrbios psíquicos $(6,4 \%)$ e meningite cisticercótica $(4,9 \%)$. As manifestą̧ōes clínicas, de acordo com a atividade da doença, são apresentadaś na Tabela 3.

Tabela 3. Manifestą̧öes clínicas e atividade da neurocisticercose dos 262 pacientes residentes em Ribeiräo Preto, notificados no periodo de outubro-1992 a dezembro-1995.

\begin{tabular}{lcccc}
\hline Manifestaçoes clínicas & Ativa & Inativa & Total & Percentagem (\%) \\
\hline Epilepsia & 28 & 179 & 207 & 79,0 \\
HIC & 5 & 5 & 10 & 3,8 \\
Meningite & 7 & - & 7 & 2,7 \\
Cefaléia & - & 6 & 6 & 2,3 \\
Psiquica & 2 & 4 & 6 & 2,3 \\
Epilepsia + HIC & 4 & 1 & 5 & 1,9 \\
HIC + Psiquica & 1 & 4 & 5 & 1,9 \\
Assintomático & - & 5 & 5 & 1,9 \\
Epilepsia + Meningite & 4 & - & 4 & 1,5 \\
Epilepsia + Psíquica & 1 & 2 & 3 & 1,1 \\
Meningite + HIC & 2 & - & 2 & 0,7 \\
Epilepsia + HIC + Psíquica & - & 1 & 1 & 0,4 \\
Medular & 1 & - & 1 & 0,4 \\
Total & 55 & 207 & 262 & 100 \\
\hline
\end{tabular}


Tabela 4. Exames do líquido cefalorraquidiano e de tomografia computadorizada do crânio dos 262 pacientes residentes em Ribeirão Preto, notificados no periodo de outubro-1992 a dezembro-1995.

\begin{tabular}{|c|c|c|c|c|c|c|c|}
\hline LCR & Pleocitose & ELISA & $\begin{array}{l}\text { Pleocitose } \\
\text { + ELISA }\end{array}$ & Normal & NR & Total & $\begin{array}{c}\text { Percentagem } \\
(\%)\end{array}$ \\
\hline Cisto & 1 & 2 & 7 & 10 & 3 & 23 & 8,8 \\
\hline Calcificação & 1 & 1 & 2 & 12 & 193 & 209 & 79,8 \\
\hline Cisto+ calcificação & 3 & 3 & 14 & 3 & 5 & 28 & 10,7 \\
\hline Normal & - & - & 1 & - & - & 1 & 0,4 \\
\hline NR & - & 1 & - & - & - & 1 & 0,4 \\
\hline Total & 5 & 7 & 24 & 25 & 201 & 262 & 100 \\
\hline
\end{tabular}

TC, tomografia computadorizada do cránio; LCR, líquido cefalorraquidiano; ELISA, positividade do teste imunoenzimático para cisticercose; NR, nāo realizado.

Os exames da TC e do LCR dos 262 pacientes são apresentados na Tabela 4. $O$ principal critério para o estabelecimento do diagnóstico de NCC foi a TC, com um total de 260 casos $(99,2 \%)$, sendo a calcificação patológica intracraniana a anormalidade mais frequentemente encontrada $(90,4 \%)$. Lesōes hipodensas (cistos), com ou sem calcificações, foram detectadas em 51 pacientes $(19,4 \%$ ); dentre estes, 43 foram submetidos ao exame do LCR que evidenciou pleocitose e/ou positividade na prova de ELISA em 30 (69,7\%) deles. O teste de ELISA foi positivo em $31(50,8 \%)$ dos 61 pacientes submetidos ao exame do LCR. Em 29 pacientes (11\%) o diagnóstico foi confirmado por anormalidades em ambos os exames (ELISA e cistos e/ou calcificações). Em apenas 2 pacientes o diagnóstico foi definido apenas através do LCR. A RNM evidenciou cistos em 4 pacientes, confirmando os achados da TC realizada previamente.

\section{DISCUSSĀO}

A Organizaçāo Panamericana da Saúde (OPAS) considera a inexistência da notificação da cisticercose na América Latina um obstáculo para o planejamento de estratégias de prevenção ${ }^{24}$. Para suprir esta lacuna, recomenda como método alternativo a investigação de NCC nas necrópsias de hospitais gerais. A maioria dos estudos necroscópicos, no entanto, é procedente de hospitais universitários ${ }^{1,3,11,27,32}$, acarretando a ocorrência de um viés de seleção. Os pacientes autopsiados em hospitais universitários sāo altamente selecionados pois, sendo estes direcionados ao atendimento terciário, há tendência de concentrar os casos mais graves e as necrópsias serem voltadas frequentemente ao esclarecimento de casos duvidosos. Tavares $\mathrm{Jr}^{40}$ ressalta ainda a influência da participação de um patologista geral ou de um neuropatologista, de sua experiência, do número de cortes no encéfalo e do preparo prévio da peça anatômica na detecção de NCC. Por estas razōes, embora sejam úteis na caracterização de áreas endêmicas, os dados necroscópicos nāo refletem a verdadeira prevalência populacional.

A prevalência calculada através de testes imunológicos no soro como o de ELISA ${ }^{5.9 .15,25,34,44,45}$ tem sua validade questionada pelo seu baixo nivel de sensibilidade e de especificidade ${ }^{28}$, sendo este melhor indicador de teníase ${ }^{5}$ que de $\mathrm{NCC}^{31}$. Tem sido sugerido, como melhor alternativa, o enzyme-linked immunotransfer blot (EITB) no soro ${ }^{13,30,42,43}$ ou na saliva ${ }^{16}$. Entretanto, o EITB apresenta baixa sensibilidade na deteç̧ão de pacientes com cisticercose única, especialmente quando calcificada ${ }^{46}$ e seus resultados são frequentemente discrepantes com os achados da TC $^{18}$.

Embora a TC seja considerada método de escolha no diagnóstico da $\mathrm{NCC}^{24}$, o potencial risco à saúde humana inviabiliza sua utilização no estudo populacional envolvendo indivíduos assintomáticos. Por outro lado, o elevado custo torna proibitiva a opção pela RNM, particularmente 
nos países em desenvolvimento onde a NCC é endêmica. A investigaçāo da frequência de NCC nos serviços de neuroimagem é útil para a detecção de novas áreas endêmicas ${ }^{19}$ mas, pelo viés de seleçāo, não permite a correta avaliação da prevalência populacional.

É imprescindível a uniformização dos critérios de investigação epidemiológica da NCC para a análise comparativa da prevalência em diferentes localidades ${ }^{24} \mathrm{e}$ a notificação compulsória é recurso plenamente válido para este fim. Adicionalmente, o mapeamento do local de residência dos casos notificados pode permitir, ao nível da comunidade, melhor direcionamento das medidas de prevenção às áreas mais afetadas. Assim, fundamentado nos dados do presente estudo, está em elaboração um programa educativo priorizando as zonas norte e oeste do nosso Município.

Em Ribeirão Preto, a implantação da notificação representou apenas a primeira etapa de programa mais amplo de prevenção, denominado Af̧ôes de Controle da Teniase e da Cisticercose em Ribeirāo Preto. Elaborado em 1988, em conjunto com os Serviços de Vigilância Epidemiológica do Município e do Estado de Sāo Paulo, este projeto compreeende a adoção simultânea e integrada de várias medidas voltadas ao combate da NCC ${ }^{39}$. A obtenção do coeficiente de prevalência foi fundamental para superar o ceticismo inicial quanto à necessidade e à conveniência do projeto, constituindo-se, atualmente, numa arma poderosa na reinvidicação consubstanciada de providências junto às autoridades govemamentais e 6rgãos públicos.

A situaçāo da NCC não está sob controle no nosso Município pois $21 \%$ dos casos apresentam a forma ativa. Esta situação deve servir de alerta para a necessidade da adoção imediata das medidas de prevenção. Em contraposição, a deteç̧ão hipotética apenas da forma inativa seria indício da inexistência de contaminaçāo recente, podendo ser observada em comunidades onde a NCC estivesse erradicada. Tal situação poderia até mesmo representar corolário de um programa de prevenção bem sucedido.

As manifestaçōes clínicas da NCC são pleomórficas, inexistindo um quadro patognomônico. O predomínio da epilepsia e da síndrome de HIC observado em nosso material é concordante com os dados da literatura $24,8,14,20,26,35,36,37,38,41$. Foram detectados $5(1,9 \%)$ indivíduos assintomáticos, diagnosticados através da constatação fortuita de calcificaçōes na TC realizada por traumatismo cranioencefálico. Outros 6 pacientes $(2,3 \%)$ apresentaram cefaléia como sintoma isolado, na ausência de dados clínico-laboratoriais suficientes para enquadramento quer como meningite quer como $\mathrm{HIC}$. $\mathrm{Na}$ literatura, a cefaléia como sintoma isolado foi constatada em $3,4 \%^{22}$ e $4,6 \%$ dos casos ${ }^{38}$. Vinte pacientes $(7,6 \%)$ apresentaram associação de dois ou mais tipos diferentes de manifestação neurológica, na assim denominada forma combinada ${ }^{20,37,38}$. O acometimento de outros orgãos $e$ sistemas além do sistema nervoso não foi relatado em qualquer dos casos notificados.

As graves consequências individuais e sociais da NCC são reforçadas pelo envolvimento do período mais produtivo da vida: $64,8 \%$ dos pacientes pertenciam à faixa etária entre 20 e 49 anos. Vinte e nove pacientes (11\%) foram hospitalizados pela NCC e $9(3,4 \%)$ submetidos a algum tipo de intervenção neurocirúrgica: derivação ventrículo-peritoneal ( 6 casos), extirpação de cistos do III ventrículo ( 1 caso), do IV ventrículo ( 1 caso) e do canal raquidiano ( 1 caso). Nove pacientes $(3,4 \%$ ) apresentaram sequelas neurológicas altamente incapacitantes: demência ou retardo mental ( 5 casos), hemiparesia (2 casos), amaurose em outro, todos por complicação da síndrome de HIC; outro paciente apresentou paraparesia crural com distúrbio esfinctérico por cisticerco no canal raquidiano. A elevada frequência de sequelas confirma a síndrome de HIC como a manifestação mais grave da NCC, merecendo o rótulo de forma maligna, como assinalado por Lima ${ }^{20}$. $O$ envolvimento medular na NCC, embora infrequente, é também motivo de grande preoçupação pois, mesmo com a extirpação de cisticercos do canal raquidiano, é frequente a evolução para paraparesia crural como sequela ${ }^{10}$.

Embora compulsória, a notificação da NCC está aquém da realidade. A subnotificaçāo é suspeitada pela ausência de notificações procedentes de alguns hospitais e de serviços de neuroimagem. Segundo Fischman ${ }^{17}$, há certo descaso pela notificação por parte dos médicos e de outros profissionais da área de saúde, muitas vezes devido à falta de credibilidade pois não se espera que providências sejam tomadas. 
A implantação da notificação da cisticercose apresenta um obstáculo adicional, pois envolve mudança de hábitos por parte da classe médica. En contraposiçăo a outras doenças infecciosas cuja notificaçăo é realizada habitualmente pelo serviço de enfermagem dos hospitais por ocasiăo da internação, a cisticercose $\varepsilon$ diagnosticada mais frequentemente nos consultórios e ambulatórios. Assim, a comunicação dos casos depende de colaboração ativa dos médicos assistentes, preenchendo pessoalmente a ficha de investigaçāo epidemiológica. A implantação da notificação deve, portanto, ser precedida e acompanhada de insistentes campanhas de divulgação sobre sua importância e finalidade, dirigidas particularmente aos neurologistas, neurocirurgiōes e radiologistas. A consolidaçāo, por sua vez, depende da manutenção da motivação através da divulgação dos resultados práticos das providências tomadas e de seus beneficios à comunidade. A implantação da notificação de forma coercitiva, sem a adequada conscientização de sua importância, pode redundar em total fracasso, tomando a NCC apenas mais uma no já imenso rol de doenças infecciosas subnotificadas.

Um dos benefícios diretos da notificação compulsória à população é a visita domiciliar para investigação de teníase e/ou de outros fatores predisponentes à contaminação. Além da orientação das medidas de prevençāo, o Serviço de Vigilância Epidemiológica do Município tem fornecido, gratuitamente, medicamentos antiparasitários, de acordo com o exame coproparasitológico dos familiares. Paralelamente, o Serviço de Vigilância Sanitária do Municfpio vem fiscalizando a qualidade da carne e de verduras consumidas pela população, num trabalho conjunto com o Instituto Adolfo Lutz de Ribeirão Preto. As informaçōes sobre os benefícios da notificação têm sido divulgadas à classe médica através do Departamento de Neurologia e Neurocirurgia do Centro Médico de Ribeirão Preto.

A escassez de dados na literatura sobre a prevalência fundamentada na notificaçāo dificulta a confrontação dos nossos resultados. No México, onde a cisticercose é doença de notificação compulsória desde $1979^{12}$, o coeficiente de prevalência foi, até 1993 , de $0,6 / 100000$ habitantes ${ }^{29}$. No Equador, em 1990, o coeficiente foi 1,14/100000 habitantes ${ }^{24}$. No Brasil, 0 único indicador de prevalência baseado na notificação compulsória é o do Estado do Paraná com 1,27/100000 habitantes ${ }^{6}$, no periodo 1993-1994. E muito provável que esteja ocorrendo subnotificação nestas localidades pois Schenone et $\mathrm{al}^{33}$ estimaram que a prevalência média da NCC na América Latina seja de 100 casos/100000 habitantes.

É intrigante a constatação desta elevada prevalência em Ribeirāo Preto, uma cidade dotada de alto nivel de urbanização e de saneamento ambiental, com população ostentando um invejável padrăo sócio-econômico-cultural e uma das maiores rendas per capita do pars. Qual seria, então, a prevalência nas localidades mais carentes do Brasil? Sugerimos que a notificaçāo da NCC seja também implantada em outras localidades e, se possível, em todo o território nacional.

Agradecimentos - Agradecemos aos Profs. Drs. Antonio Spina-França, José Antonio Livramento, Luis dos Ramos Machado e José Paulo Smith Nobrega pelas valiosas sugestōes na elaboraçāo do projeto: Af̧ōes de Controle da Teníase e da Cisticencose em Ribeiräo Prefo e ao Conselho Nacional de Desenvolvimento Cientifico e Tecnológico (CNPq) pelo apoio financeiro (Processo 300336/93-4).

\section{REFERENCIAS}

1. Agapejev S. Incidencia de neurocisticercose no Hospital das Clínicas da Faculdade de Medicina de Botucatu da Universidade Estadual Paulista. Tese. Faculdade de Medicina de Ribeir̋̄o Preto da Universidade de Sæo Paulo Ribeirăo Preto, 1994.

2. Alarcón T, Olivares L. Cisticercosis cerebral: manifestaciones clínicas en un medio de alta prevalencia. Rev Invest Clin 1975;27:209-215.

3. Briceño CE, Biagi F, Martinea B. Cisticercosis: observaciones sobre 97 casos de autopsia. Prensa Med Mex 1961 ;26:193-197.

4. Brotto W. Aspectos neurológicos da cisticercose. Arq Neuropsiquiatr 1947;5:258-294.

5. Camacho SD, Ruiz AC, Beltrin MU, Willms K. Serology as an indicator of Taenia solium tapeworm infections in a rural community in Mexico. Trans R Soc Trop Med Hyg 1990;84:563-566.

6. Camargo NJ. Epidemiological status of the teeniasis/cysticercosis in the State of Parank (south region of Brazil) and the control strategies. In PAHONWHO. Taeniasis/cysticercosis complex: future trends toward ies control. Geneva: WHO, 1995.

7. Canelas HM. Neurocisticercose: incidencia, diagnostico e formas clínicas. Arq Neuropsiquiatr 1962;20:1-16.

8. Canelas HM. Cisticercose do sistema nervoso central. Rev Med (Sto Paulo) 1963;47:75-89.

9. Coker-Vann MR, Subianto DB, Brown P, Diwan AR, DesowitzR, Garruto RM, Gibbs Jr CJ, Gajdusek DC. ELISA antibodies to cysticerci of Taenia solium in human populations in New Guinea, Oceania, and Southeast Asia. Southeast Asian J Trop Med Publ Health 1981;12:499-505. 
10. Colli BO, Assirati JA Jr, Machado HR, Santos F, Takayanagui OM. Spinal cysticercosis. Arq Neuropsiquiatr 1994;52:187-199.

11. Costa-Cruz JM, Rocha A, Silva AM, Moraes AT, Guimarāes AHB, Salomão EC, Alcântara TM. Ocorrência de cisticercose em necrópsias realizadas em Uberlândia, Minas Gerais, Brasil. Arq Neuropsiquiatr 1995;53:227-232.

12. Damonte-Vjcello LJ. Desconocimiento de la epidemiologia de la cisticercosis en México. Salud Publ Mex 1983;25:301-305.

13. Diaz JF, Verastegui M, Gilman RH, Tsang VCW, Pilcher JB, Gallo C, Garcia HH, Torres P, Montenegro T, Miranda E. Immunodiagnosis of human cysticercosis (Taenia solium): a field comparison of an antibody-enzyme-linked immunosorbent assay (ELISA), an antigen-ELISA, and an enzyme-linked immunoelectrotransfer blot (EITB) assay in Peru. Am J Trop Med Hyg 1992;46:610-615.

14. Dixon HBF, Lipscomb FM. Cysticercosis: an analysis and follow-up of 450 cases. Medical Research Council Special Report Series No. 299. London: Privy Council, 1961.

15. Dumas M, Grunitzky E, Deniau M, Dabis F, Bouteille B, Belo M, Pestre-Alexandre M, Catanzano G, Darde ML, D'Almeida M. Epidemiological study of neurocysticercosis in northern Togo (West Africa). Acta Leiden 1989;57:191-196.

16. Feldman M, Plancarte A, Sandoval M, Wilson M. Flisser A. Comparison of two assays (EIA and EITB) and two samples (saliva and serum) for the diagnosis of neurocysticercosis. Trans R Soc Trop Med Hyg 1990;84:559-562.

17. Fischmann A. Vigilância epidemiológica. In Rouquayrol MZ. Epidemiologia e saúde. Ed4. Rio de Janeiro: MEDSI, $1994 ; 421-441$.

18. Garcia HH, Herrera G, Gilman RH, Tsang VCW, Pilcher JB, Diaz JF, Candy EJ, Miranda E, Naranjo J. Discrepancies between cerebral computed tomography and western blot in the diagnosis of neurocysticercosis. Am J Trop Med Hyg 1994;50:152-157.

19. Gonçalves-Coêlho TD, Coêlho MDG. Cerebral cysticercosis in Campina Grande, Paraíba - northern Brazil: computerized tomography diagnosis importance. Arq Neuropsiquiatr 1996;54:94-97.

20. Lima JGC. Cisticercose encefálica: aspectos clínicos. Tese. Escola Paulista de Medicina Sāo Paulo, 1966.

21. Machado LR, Nóbrega JPS, Barros NG, Livramento JA, Bacheschi LA, Spina-França A. Computed tomography in neurocysticercosis: a 10-year long evolution analysis of 100 patients with an appraisal of a new classification. Arq Neuropsiquiatr $1990 ; 48: 414-418$.

22. Mc Cormick GF, Zee C, Heiden J. Cysticercosis cerebri: review of 127 cases. Arch Neurol 1982;39:534-539.

23. Minguetti G, Ferreira MVC. Computed tomography in neurocysticercosis. J Neurol Neurosurg Psychiatry 1983;46:936-942 .

24. Organización Panamericana de la Salud. Epidemiologia y control de la teniasis/cisticercosis en America Latina. Version 3.0. Washington:OPS/OMS, 1994.

25. Pammenter MD, Rossouw EJ, Dingle CE. Serological detection of cysticercosis in two rural areas of South Africa. Trans $\mathbf{R}$ Soc Trop Med Hyg 1987;81:242-244.

26. Pupo PP. Cysticercosis of the nervous system: clinical manifestations. Rev Neuropsiquiat (Lima) 1964;27:70-82.

27. Rabiela-Cervantes MT, Rivas-Hernández A, Rodriguez-Ibarta J, Castillo-Medina S, Cancino FM. Anatomopathological aspects of human brain cysticercosis. In Flisser A, Willms K, Laclete JP, Larralde C, Ridaura C, Beltrán F (eds). Cysticercosis: present state of knowledge and perspectives. New York: Academic Press, 1982:179-200

28. Ramos-Kuri M, Montaya RM, Padilla A, Govezensky T, Díaz ML, Sciutto E, Sotelo J, Larralde C. Immunodiagnosis of neurocysticercosis: disappointing performance of serology (enzyme-linked immunosorbent assay) in an unbiased sample of neurological patients. Arch Neurol 1992;49:633-636.

29. Sarti E. La taeniasis y cysticercosis: perspectiva historica, estado actual y necesidades futuras. In: PAHO/WHO. Taeniasjs/ cysticercosis complex: future trends toward its control, Washington: PAHO/WHO,1995.

30. Sarti E, Schantz PM, Plancarte A, Wilson M, Gutierrez OI, Aguilera J, Roberts J, Flisser A. Epidemiological investigation of Taenia solium teniasis and cysticercosis in a rural village of Michoacan state, Mexico. Trans R Soc Trop Med Hyg 1994;88:49-52.

31. Scharf D. Neurocysticercosis: two hundred thirty-eight cases from a California hospital. Arch Neurol 1988;45:777-780.

32. Schenone H, Ramírez R, Rojas A. Aspectos epidemiológicos de la neurocisticercosis en América Latina. Bol Chil Parasitol 1973;28:61-72.

33. Schenone H, Villarroel F, Rojas A, Ramírez R. Epidemiology of human cysticercosis in Latin America. In Flisser A, Willms K, Laclette JP, Larralde C (eds). Cysticercosis: present state of knowledge and perspectives. New York: Academic Press, 1982:25-38.

34. Shasha W, Pammenter MD. Sero-epidemiological studies of cysticercosis in school from two rural areas of Transkey, South Africa. Ann Trop Med Parasitol 1991;85:349-355.

35. Sotelo J, Guerrero V, Rubio F. Neurocysticercosis: a new classification based on active and inactive forms: a study of 753 cases. Arch Intern Med 1985;145:442-445.

36. Spina-França A. Cisticercose do sistema nervoso central: consideraçōes sobre 50 casos. Rev Paul Med 1956;48:59-70.

37. Takayanagui OM. Aspectos clínicos da neurocisticercose: análise de $\mathbf{5 0 0}$ casos. Dissertaçāo de Mestrado. Faculdade de Medicina de Ribeirão Preto da Universidade de São Paulo, Ribeirão Preto, 1980.

38. Takayanagui OM. Neurocisticercose: evolução clínico-laboratorial de 151 casos. Tese. Faculdade de Medicina de Ribeirão Preto da Universidade de São Paulo Ribeirão Preto, 1987.

39. Takayanagui OM. Neurocisticercose: profilaxia. In: Machado LR, Livramento JA, Spina-França A, Nóbrega JPS (eds). Neuroinfecção-96. São Paulo: Clínica Neurológica HC/FMUSP, 1996:235-243.

40. Tavares AR Jr. Aspectos neuropsiquíáricos da neurocisticercose humana. Tese. Escola Paulista de Medicina Sāo Paulo, 1994.

41. Trelles JO, Lazarte J. Cisticercosis cerebral: estudio clínico, histopatológico y parasitológico. Rev Neuropsiquiat (Lima) 1940;3:393-511.

42. Tsang VCW. Immunologic responses to larval Taenia solium infection and the application of immunodiagnostic tools in control and epidemiology. In PAHO/WHO. Taeniasis/cysticercosis complex: future trends toward its control, Washington: PAHO/WHO,1995. 
43. Tsang VCW, Brand JA, Boyer AE. An enzyme-linked immunoelectrotransfer assay and glycoprotein antigens for diagnosing human cysticercosis (Taenia solium). J Infect Dis 1989;19:50-59.

44. Vaz AJ, Hanashiro ASG, Chieffi PP, Ferreira AW. Frequência de indivíduos com anticorpos séricos anti-Cysticercus cellulosae em cinco municipios do Estado de São Paulo. Rev Soc Bras Med Trop 1990;23:97-99

45. Vianna LG, Macédo V, Costa JM, Mello P, Souza D. Estudo soroepidemiológico da cisticercose humana em Braślia, Distrito Federal. Rev Soc Bras Med Trop 1986;19:149-156.

46. Wilson M, Bryan RT, Fried JA, Ware DA, Schantz PM, Pilcher JB, Tsang VCW. Clinical evaluation of the cysticercosis enzyme-linked immunoelectrotransfer blot in patients with neurocysticercosis. J Infect Dis 1991;164:1007-1009. 